\title{
Thought about Postgraduate Education Management Mode in China
}

\author{
Meihong Chen ${ }^{1}$, Yongmei Hao ${ }^{1}$ \\ ${ }^{1}$ School of Physics and Optoelectronic Engineering Nanjing, University of Information Science and \\ Technology, Nanjing, 210044, China
}

Keywords: Postgraduate education, Management mode, Education system

\begin{abstract}
In current stage, there are many defects in postgraduate education management mode in China, such as serious hysteretic nature of enrollment system, single and one-sided educational mode and no attention to cultivating practical ability. These problems result in disunity of postgraduate quality and large ability difference and seriously affect development of postgraduate quality education and talent cultivation quality. Thus, this paper discusses postgraduate education management mode and proposes some individual ideas about postgraduate education management reform.
\end{abstract}

\section{Introduction}

As postgraduate education scale expands, constructing a set of management mode suitable for postgraduate education becomes a major problem faced by current colleges. Postgraduates are the main force for national scientific research work. The support of creative talents with strong specialty literacy can bring development and innovation of China's science, technology, medical treatment and education and plays a positive promotion role for China's economic development. So, the state or education department should not just main postgraduate education methods as the key work, but also regard postgraduate education management as the precondition of cultivation. It is necessary to facilitate innovation of postgraduate education methods through reforming education management mode.

\section{Development and problems of postgraduate education management mode}

\section{Development status of postgraduate education management mode}

Complete academic degree with rational structure is established

Postgraduate management system is based on operation mechanism. Universities mainly own academic degree authorization and declaration mechanism, examination, approval and evaluation mechanism for doctors or masters, examination, approval and evaluation mechanism for supervisors, postgraduate enrollment, education, cultivation and academic degree conferring mechanisms. The above mechanisms have been relatively perfect and complete in the process of postgraduate education mode development and can play a very effective role in postgraduate education. With the development of university and postgraduate education mode, China's postgraduate education system also becomes very rational in continuous perfection, and postgraduate, doctor and supervisor team building is becoming increasingly rational. For example, trapezoidal structure is constructed in universities. The upper structure is the highest unit of postgraduate education and cultivation graduate school. Postgraduate education and cultivation unit is in the middle position. Authorized postgraduate cultivation unit is at the bottom.

To make talent training comply with university education development mechanism and the needs of the state for professional talents in each industry, universities set up special academic degree system. Since the last century, China's postgraduate academic education has been constructed preliminarily. Through construction of such mechanism, university postgraduate talents own very professional ability and knowledge quality. Meanwhile, master and doctor degree authorization channels are established. This plays a positive role in training talents with high professional quality and strong comprehensive ability. 
Talents with high professional ability are trained for national development

In 1970s, postgraduate education developed and academic degree system was built. Thus, postgraduate cultivation gradually walks the way of postgraduate and scale. Postgraduate training quality also improves. Postgraduate education with rapid development drives development of all walks of life in China and provides many high-level talents with high professional quality and strong practical ability for education, culture, economy and national defense construction. Thus, development and reform of China's scientific research and education mechanism are driven. Talent support is offered for socialist construction and science \& technology development.

\section{Major problems faced by China's postgraduate education management mode}

Postgraduate enrollment system is one-sided

Postgraduate enrollment system in China is one-sided. Main channels for postgraduate enrollment include examination enrollment and assessment of the test score. After enrollments smoothly pass the first assessment of scientific research institutions, they will receive reexamination. Such examination system is very to the disadvantage of improving postgraduate pool quality and level. Postgraduate examination subjects include: politics, foreign language, mathematics and specialized course. In view of effects of regional difference on specialized course difference, when the state formulates uniform minimum passing score, it will screen according to overall distribution of test scores. In addition, all universities will enroll postgraduates in accordance with the minimum score in combination of respective specific conditions. Only the examinees whose preliminary test score reaches national minimum passing score can smoothly enter the next round of reexamination. It thus can be seen that postgraduate entrance examination score is a decisive factor of enrollment. So, most examinees make sufficient preparatory work for postgraduate entrance examination during learning undergraduate courses and boost examination ability greatly. However, they ignore promotion of their practical ability and the capacity for scientific research. This affects quality and level of postgraduate pool.

\section{Ability training mode is single}

Generally, in postgraduate education process, ability training mainly proceeds from three aspects: teaching means, practice research and graduation thesis. Under traditional education management mode, postgraduates fail to well cognize each course and are not very clear about the ability which should be owned. They do not pay much attention to their own ability, either. Course learning, graduation thesis design and writing are very important contents in postgraduate career planning and must be compelled. But, the two contents cannot be conducted according to course standards. Many postgraduates start to prepare and design their graduation thesis during study and ignore course study and practical exploration. Aiming at these problems, the main causes involve the following: teaching course still follows traditional mode, but such mode pays no attention to cultivation of students' interest and ability. It is thus difficult to arouse students' learning interest and learning autonomy. Thus, students' independent innovation ability is poor. Secondly, scientific research team building of many universities is insufficient. Theoretical knowledge teaching is valued, and practical activities are very limited. Thus, students' ability to apply knowledge is poor. Finally, course setting cannot highlight students' employment orientation. Public degree courses and foundation courses are still the subjects, while courses related to students' career are few.

Ability acceptance inspection is deficient

Postgraduates' ability acceptance inspection way mainly refers to graduation postgraduate design and writing quality. Writing level of professional thesis can reflect postgraduates' learning degree and practical ability. But, it is a little improper to regard it as the sole index to evaluate postgraduates' ability. Thus, postgraduates' ability acceptance inspection should highlight students' personality development and practical ability development, deem practical ability and graduation thesis quality in current education management training as key work of acceptance inspection and reflect it in oral defense form. 


\section{Methods to improve postgraduate education management level}

\section{To construct “demand-orientation” mechanism for education cultivation}

Whether postgraduate education can adapt social development and reform? The decisive factor is that postgraduate education can satisfy social talent demand, maintain equilibrium state with talent supply and demand and meet increasing trend of social laborers. With development of science and technology, postgraduate education can adapt demand of various talents.

China's postgraduate education scale and structure should be able to adapt economic development and make market mechanism adapt talent supply and demand system in society so that talent cultivation reflects scale and hierarchy needs. Talent cultivation mechanism can be adjusted in sufficient combination of relevant cultivation units and by use of their specialty advantage. Besides, the relationship between national guidance policy and market demand should be matched well. Hence, postgraduate management needs to construct "demand orientation" mechanism and universities should enroll students according to economic development. The state may loosen enrollment plan for specific specialty. The support funds can be adjusted according to actual enrollment so that postgraduates can smoothly fuse in national economic construction and establish multi-level and all-round cooperation relationship with each sector, such as university-enterprise cooperation teaching, oriented training plan and cooperation training. Business, industry, school and other scientific research institutions can be effectively joined to make positive response to economic construction. Rational mode may be adopted to new disciplines and inter-disciplines suitable for student development can be constructed to form flexible and open education management mode.

In terms of discipline structure, it should be based on national economic development. Since social and economic development continuously reforms and adjusts, talent cultivation is necessary to adjust after certain period in accordance with current education development trend. However, resource waste will be caused, and discipline distribution cannot reach balance. Hence, it is required to properly increase the number of engineering postgraduates enrolled, boost fusion of new disciplines and basic disciplines, increase student enrollment force and scale of education specialty and agro-ecology management specialty and optimize discipline structure. In terms of academic degree type, it is required to expand the scale of full-time postgraduates and professional degree postgraduates, boost the proportion of professional postgraduates and enhance cultivation force of applied talents. In the aspect of professional degree postgraduate education, some western developed countries do very well. China can learn western education practice methods in education management mode. Although postgraduate education management mode developed late, it also has developed to some extent after innovation and exploration for many years. Previously, professional degree education has become a characteristic education management mode and has been brought in the total outline of education development. Hence, the state should fully combine modern postgraduate education cultivation mode and enhance the relation between postgraduate education and vocational qualification so as to drive social reform and boost postgraduate management level.

\section{To reform enrollment system}

Based on the above discussion, postgraduate enrollment has some serious defects in many aspects. Examination still occupies a leading position, which seriously affects selection of applied talents. Therefore, reestablishing postgraduate enrollment system and highlighting students' ability selection are very important. To be more specific, individual ideas are as follows:

1). Firstly, the proportion of preliminary test should expand, and the enrollment score should be reduced. Besides, ability assessment in the reexamination should be increased so as to eliminate the phenomenon of valuing the score of general knowledge courses and form the enrollment system of "loose enrollment system and strict examination system".

2). Secondly, ability should serve as additional score. Universities can refer to postgraduate admissions eligibility of universities and scientific research institutions when increasing scores of examinees. Relevant certificates show when examinees own professional ability, universities may give them certain additional score. In such way, examinees' ability should stand out. 
3). The quota of postgraduate admissions should increase. The survey of some universities indicates more than half university teachers reflect postgraduates recommended by universities have high professional ability, and the quality of student pool is very high. This is because postgraduates own the conditions of being recommended for admission to school and have high level. Students recommended for admission generally include the following parts: some firmly grasp knowledge, so they have strong learning ability in postgraduate stage and can make the knowledge coherent; some students have strong scientific research ability. In postgraduate assessment process, their scientific research ability is restricted. In postgraduate stage, their scientific research foundation is strong and they own high scientific research level.

\section{To enhance postgraduate ability cultivation}

In current stage, postgraduate cultivation mode of many universities is single, which is reflected in the following aspects: firstly, too single cultivation mode ignores students' practical ability. Finally, postgraduates increase the degree of valuing course scores and graduation thesis; secondly, teaching mode is single. Course explanation and teaching method are not flexible enough. In allusion to these problems, starting from the perspective of education policy, relevant government departments should positively guide postgraduates and enhance postgraduate ability cultivation. Universities at all levels should always stick to education policy issued by the state and push postgraduate ability cultivation to a new level according to their characteristic teaching means.

\section{Conclusions}

This paper mainly deeply analyzes development status of postgraduate education management mode and puts forward some ideas for improving postgraduate education management. To achieve innovation, postgraduate education management mode should be enhanced from such aspects as training mode, enrollment way and ability cultivation. It is necessary to highlight postgraduate ability cultivation, attach importance to their scientific research ability, and make postgraduates become talents needed by the state and society and contribute to national construction.

\section{References}

[1] Chen Meihong, Exploration of postgraduate teaching reform thought. China Adult Education, 2013,18:135

[2] Zheng Yichun, Hu Baogui, Analysis of postgraduate education management mode under higher education management system frame. Collected works of 2008 annual meeting and university management international forum of Higher Education Management Research Society under Higher Education Research Academy of China, 2010:507-512

[3] Chen Meihong, My opinion on “education of love” in institutions of higher education. Education Teaching Forum, 2014,44:229

[4] Xu Yuanyuan, Li Su, Construction of postgraduate education management mode adapted to characteristics of masters of engineering - practice of masters of engineering cultivation in Yunnan University. Collected papers of the fourth masters of engineering postgraduate education seminar, 2004:235-239

[5] Ji Hong, Jiang Yaoguang, Practice and exploration of postgraduate education management information system of China Academy of Space Technology. Collected papers of the fourth masters of engineering postgraduate education seminar, 2011:179-185

[6] Qu Yongqiang, Hu Liping, Firm establishment of management subject position of secondary colleges and construction of postgraduate education and management mode integrating party and government. Journal of Kunming Medical College, 2010,29(z2):133-136 
[7] Shang Shouhong, Mei Yan, Study on postgraduate management education of scientific research institution -exploration and practice of postgraduate management and education in 63820 Army [AC]. Collected papers of the 12th "21 century continuing education forum”. 2012:186-189

[8] Chen Meihong, On honesty shortage phenomenon of universities. Education Teaching Forum, 2013,3:108 